\title{
Towards Responsible Action through Agroecological Education
}

\author{
Geir Lieblein*, Charles Francis \\ Department of Plant and Environmental Sciences, Norwegian University of Life Sciences \\ P.O. Box 5003, 1432 Ås, Norway
}

Received: 2 December 2006. Accepted: 2 January 2007

\begin{abstract}
In the Agroecology MSc Program in the Nordic Region, conventional training of routine skills and memorizing facts, principles and theories are only two components of the educational activities. We have established a dual learning ladder metaphor to explore the expanded learning process. To establish context and build relevance, student teams begin their studies in agroecology by working with farmers and other key clients in the food system. After exploring the current situation, students can step down the learning ladder to acquire additional needed information and skills. Next they explore the links between theory and application, and we provide a safe space to experiment with putting knowledge into directed action. To help clients plan for a desirable future in farming and food systems, students step up the learning ladder to practice their ability to think creatively about the future, and then to evaluate the expected impacts and potential implications of alternative scenarios. Underlying the learning of skills, principles, and methods for action are the internal values and attitudes that will motivate and drive students in their future work. These include individual learning as a process of practicing, assimilating, connecting, creating, and acting with responsibility. In this paper we describe the educational process used in agroecology, with the dual learning ladder as metaphor for both cognitive learning and personal growth.
\end{abstract}

Key-words: agroecology, dual learning ladder, autonomous learning, action education.

\section{Introduction}

Traditional education in agriculture has focused on the biological dimensions of crop and animal production and the economic consequences of alternative systems and enterprises. This narrow emphasis on production questions and economic return in the short term leaves our graduates ill-prepared to deal with uncertainty and complexity in designing future systems, and generally ignores the overwhelming importance of the ecological context and of social and political decisions that affect the food system. Agroecology provides a useful alternative to overcome these deficiencies in the traditional study of agricultural systems.

The production successes of the Green Revolution in the tropics and the great leap in productivity based on genetic improvement and fertilizer use in temperate regions have led many to believe that global food challenges could be solved by intensifying production on the best lands and limiting expansion into poorly suited areas (Tilman et al., 2002). This optimism ignores the political and social realities of land distribution, as well as an inability of most governments to achieve equity in access to land and resources to those who want to produce food. People will farm the land they currently have in order to survive. There have been growing concerns about the environmental impacts of agriculture, and ecological indicators must be added to the list of criteria for evaluating success of systems. Erosion of the natural resource base has been an unintended consequence of large gains in crop production, even as these gains have been consumed by a growing global population (Brown, 2006). One economic approach has been financial incentives in the form of support payments for environmentally sound soil conserving practices and systems. However, 
the majority of subsidies continue to reward high levels of production on large farms, with the result of higher land prices, further consolidation of ownership, and negative impacts on the environment (Kimbrell, 2002).

Awareness is also growing of the political and social dimensions of food production, distribution, and equity of access (Allen, 2004). Our recent definition of agroecology as the ecology of food systems (Francis et al., 2003) leads to study of agricultural systems in terms of the complexity of interactions among the biological, economic, environmental, and social factors that contribute to success or failure. To appreciate the entire ecology of the system requires study of production, processing, marketing, and consumption of food.

We find that responsible action by graduates in agriculture depends on understanding the complexity of this system. We also find that current education in agriculture is especially deficient in dealing with the complex and dynamic nature of agricultural systems, including the social and political components. In the Nordic region, a series of short courses was set up to begin to correct that situation (Lieblein et al., 1999, 2000). Since most agroecology teaching has been initiated in agronomy and other agricultural production departments, it is important that instructors become more aware of the social and ecological dimensions of agricultural systems and begin to incorporate this perspective into mainstream courses (Altieri and Francis, 1992).

Agroecology has emerged as an integrative conceptual and practical field that encompasses the ecological, social and economical dimensions of the food system. Theoretical concepts and methods to study and improve farming and food systems include the models described by Checkland (1981), the Hawkesbury spiral (Bawden, 1989; Sriskandarajah et al., 1991), and other tools for learning presented by Wilson and Morren (1990). In all cases, the methods include multiple views of systems and their components as people and their decisions impact them. It is our blending of ecology with the systems methods that give a new flavor to agricultural systems study, and promoting autonomous learning is an essential part of this approach to education.

The history of agroecology has roots in Ger- many (Friederichs, 1930) and in the U.S. (Hanson, 1939), summarized by Dalgaard et al. (2003). Blending agriculture and ecology has gained prominence over the past two decades through the writings of Caporali (1991), Altieri (1995), and Gliessman (2001). Evolution in the use of the term agroecology and the concepts evolving in application are provided in Dalgaard et al. (2003) and Francis et al. (2003). The recent books by Altieri and Nicholls (2005) and Gliessman (2006) broaden the discussion to include more social dimensions of the food system.

Why should agronomists, horticulturists, and agricultural economists deal with systems approaches, integrating social and ecological dimensions into the study of agricultural systems? As stated above, most biological and economic scientists are not well grounded in the ecological issues surrounding food systems, nor with the social science methods that are used to explore and understand nutrition, community, power relations, and equity issues (Allen, 2004). Without a broad and comprehensive analysis of the strengths and weaknesses, the opportunities and challenges found in current systems, it is highly likely that we could direct our research energies and our teaching toward low priority issues. One of the challenges of educators working with the future generation of agricultural professionals is to help them appreciate all dimensions of agricultural systems, and our approach to educating agroecologists in the Nordic Region provides one useful model.

\section{Becoming an agroecologist through action education}

The Nordic learning approach in agroecology offers an innovative alternative to a conventional curriculum in the university. Planning a curriculum in any discipline often starts with a list of courses that the faculty decides is essential. These frequently are patterned after other programs in universities that have a good reputation for research and teaching in that discipline. And often the curriculum is a collection of specialized, highly technical courses that provide unconnected competencies in important subdisciplines. Since these may be taught by some of the world's expert researchers in these topics, it is likely that students are guaranteed 
an exposure to the latest available literature and research results. Such a curriculum does not guarantee integration of information, application in a systems context, or setting priorities and sorting out what information is most important. Without practical experience in how to apply knowledge to real-world challenges, many graduates lack the confidence to meet farmers and discuss improvements in farming systems.

One strategy to improve the situation is setting up a list of competencies that will be most useful to those who graduate from a program (for example Richards, 1985; Foyster, 1990). Competence-based outcomes improve on the collection of skills and knowledge described above, especially if one of the outcomes pursued is integration of information and skills across disciplines, and the application of this learning to real-world situations and challenges. It may be successful if it prepares students to deal with uncertainty, complexity, and alternative future situations. It will not be successful if it is limited by the instructors' visions of the future. From this emerges our notion of the need to focus on how students and faculty can become agroecologists (Lieblein et al., 2000; Lieblein et al., 2004). This is important because students are becoming professionals in a new field, and instructors are continually becoming better agroecologists through their interactions with students, finding different points of view, and continuing to find new ways of seeing things (Bowden and Marton, 1998).

Action education is based on a philosophical pragmatism that proposes that we learn best by integrating theory and action. Our agroecology courses provide students with learning opportunities to gain skills, knowledge, and capacity for dealing with complexity in today's agriculture. Students use systems theory to ground their study of structure and function of agroecosystems in real situations, and then envision potential future scenarios that will help farm families achieve their perceived goals. To evaluate these scenarios, students determine to the extent possible the potential future impacts in economic, environmental, and social terms for that farm family. This process helps the teamwork with clients to design future direction and management decisions.

In a food system course, each of our student teams each work with a key client and multiple stakeholders in one county in Norway. They develop a rich picture of the food system, including resource flows and economic consequences of current activities in the county's food system. They interact with diverse stakeholders to understand the current production, processing, and food consumption patterns in the county. From the key client and others, they determine a set of goals that will lead to an improved future food system, using social, ecological and economic indicators of sustainability. Again, they envision and develop potential future scenarios that could be implemented by the community to meet those goals, and evaluate the impacts of each strategy. The results are presented not only as a team document to course instructors, but also to the key client for consideration of application in the county.

The success of the program is partly due to the focus on real situations, where students develop the individual and collective capacities for getting the skills and knowledge needed by clients in a practical situation of the farm or the county food system. But also they can apply their energy and guide their passion into study of questions that will make a difference in people's lives and well-being. We call this a step in the learning ladder where they bring attitudes and values into a process of practicing as professionals, assimilating information, and working toward responsible action (Fig. 1) although we apply this process to agriculture, and give it the name agroecology, the model could be applied to other practical fields as well. With an orientation toward action, we believe that education should prepare students to become autonomous learners who are prepared to face new situations in the future.

\section{Case studies as starting point for learning}

The case study method of learning, sometimes called problem-based learning, began in the Harvard Business School in the 1920s, and they continue to develop new cases and champion this method (for examples see http://www.hbs. edu/research/recent_cases.htm).

In general, students are put into a simulated situation and provided with information on the context and the challenge to be solved. They work through what is given, may access additional information, and try to come up with a 
logical explanation for what they provide as a solution. In most cases, they are trying to find out what really happened, that is, to find out what the instructor has in mind as the "correct" solution. The method has been widely applied in agriculture over the past twenty years, especially through leadership of the educator group at University of Minnesota, and a new book of cases has recently been published by the American Society of Agronomy (ASA, 2006). We could call this approach to case studies a learning environment of fixed answers or known solutions, where just as on an exam in a lecture course the students are trying to figure out what the instructor wants to hear.

In contrast, our approach in agroecology has been to use case studies on farms and in communities in a real-world context where the outcomes are not already determined. Students interview farmers, key clients, and others in the food system and build a rich picture of the current situation. They determine as well as possible the inputs and outputs of the systems, and go beyond the production and economics of the system to look at environmental impacts and social dimensions of the system and their implications. As students begin to envision alternatives for the future, they realize that there are no set solutions, that the future is not already determined, and that what they develop could very well be a chosen course of action by the clients. This adds realism, creates responsibility, and leads to confidence in their recommendations in the current case. It also builds a capacity for addressing future situations where the context is complex, the outcomes are uncertain, and the rules of the game keep changing as quickly as weather, economic exchange rates, and international political alliances. We find that this learning landscape is highly challenging to students, often completely daunting at first, as they realize that there is no specific answer that we are trying to squeeze out of them. But the result has been highly satisfactory, as students have told us on their evaluations. From a student in 2001: "This type of learning enabled me to grow as a person, made me aware of my own competencies, and gave me the courage to start using these in my thesis work and now also in my professional life" (quoted in Lieblein et al., 2007).

To catalyze this type of learning and help students develop a capacity for future autonomy far beyond our courses and activities, we need to recognize that each student learns in a different way, puts meaning into each experience, and develops capacity to apply that learning and hopefully go far beyond anything that we have been able to achieve in the courses. This leads to a discussion of how individual students move through the landscape, both in learning content and personal growth.

\section{Becoming an autonomous learner: enriching the process}

One of the key strategies in designing a learning landscape for students in agroecology is to create space and incentives for them to become autonomous learners. For students to progress from only learning skills and assimilating more knowledge, and especially to become discerning scholars of what is most important, they need to move beyond what is known by the instructors and the expectations in a given course or in the entire agroecology curriculum. To be able to function well in a complex future of uncertainty, it is essential that students acquire the abilities and attitudes to move toward new challenges with confidence, fully able to seek out relevant information, and apply what they have learned in new and as yet unknown situations (Bowden and Marton, 1998). This cannot be done without a high degree of capacity for autonomous learning.

Autonomous learning could be described as a student's ability to design and to critically reflect on their own learning process and environment. It builds confidence in personal abilities, a capacity for visioning future scenarios, and the skills to search out new information efficiently and as needed. It builds on the experiential learning cycle as described by Kolb (1984) and recognizes the importance of context as shown in situated learning (Lave and Wenger, 1991). We illustrate this process by providing an internal learning ladder metaphor, showing the personal growth that includes practicing skills, assimilating and integrating new information, connecting information with the real world, creating new scenarios, and putting these ideas into practical action (Fig. 1). It could be argued that the basic foundation for autonomous learn- 
ing was provided over a century ago by John Dewey (1942) in Democracy and Education and in his other writings. Important components of this education are the skills and knowledge that students themselves begin to realize are most important for their future careers.

These skills include the ability to do a thoughtful analysis of farming and food systems, at both the farm and the community or regional level. To accomplish this it is essential to go beyond the production dimension, the inputs and outputs, and the short-term economic analysis of profit and loss for each enterprise. Higher order questions involve the integration of system components, the complementarities of enterprises and human activities in the system, and the broader impacts on the family and community including the long-term sustainability of the food system. This obviously requires attention to environmental and social issues in the system, and it is essential to take a holistic approach to evaluation and assessment. We have found that this is best accomplished when working on farms and in communities, immersed in the context where the challenges reside. In our experience in the Nordic Agroecology education, students have been highly motivated by working directly with clients and have captured the energy from the farmers and other stakeholders as well as added their own enthusiasm for the tasks. This type of learning experience is often lacking in most of our curricula in agriculture today.

Beyond the skills and knowledge that students acquire from organized classes, discussions, and tours, we find it important for them to explore and develop the values and attitudes that will sustain professionals through a career in what is often an uncertain future. Students may come into a program with a high level of motivation to serve others, and when they are pushed into the classroom and given a set of tasks to memorize facts or only solve problems where the answers are already known, they may lose the edge of excitement that brought them to the educational table in the first place (Bowden and Morten, 1998). Some medical schools have found that teaching only anatomy and having students memorize Latin names of muscles and bones as a primary activity in the first year may favor those who can assimilate information in that way, but screen out those with a real con- cern for people. The alternative used in University of Troms $\varnothing$, the Oregon Health and Sciences University, and elsewhere is to put students on the floor with patients from the first week, wearing a white coat and stethoscope, working under supervision of skilled instructors, but responsible for patient histories, observation, and preliminary diagnoses. This strategy affirms the commitment of students to help patients and reinforces their desire later to learn the details needed to become good physicians and nurses. It is an example of what Salomonsson et al. (2005) called "just-in-time education".

The assignments, the discussions, and the case studies appear to be successful in helping students to become more autonomous learners, and thus better able to cope with complexity in the future. One of the agroecology students in 2004 described this well: "The agroecology semester generally gave me a deeper sense of self awareness, making me more conscious and interested in my learning process, and that of those I work with. The semester completely changed my views on education, moving from a quest for knowledge and answers to an exploration of questions, their underlying values, and of ways to bring about meaningful change as a community".

\section{Education towards responsible action: A dual learning ladder}

Numerous authors have explored the steps in learning and created a hierarchy of knowledge, often starting with Benjamin Bloom's (1956) taxonomy that goes from memorizing facts, through comprehension to application, analysis, synthesis, and evaluation. Based on the work of Kurt Lewin, David Kolb (1984) described learning as a cycle that moves from concrete experience to reflective observation, abstract conceptualization, and active experimentation. Building on Blooms concept of a learning ladder and Kolb's emphasis on linking cognition and practice we have developed a learning ladder metaphor that integrates a personal dimension including values, attitudes, and emotions into the learning landscape, in addition to cognitive elements (Fig. 1).

Steps in the external learning ladder are illustrated in Figure 1, where lower level skills are 


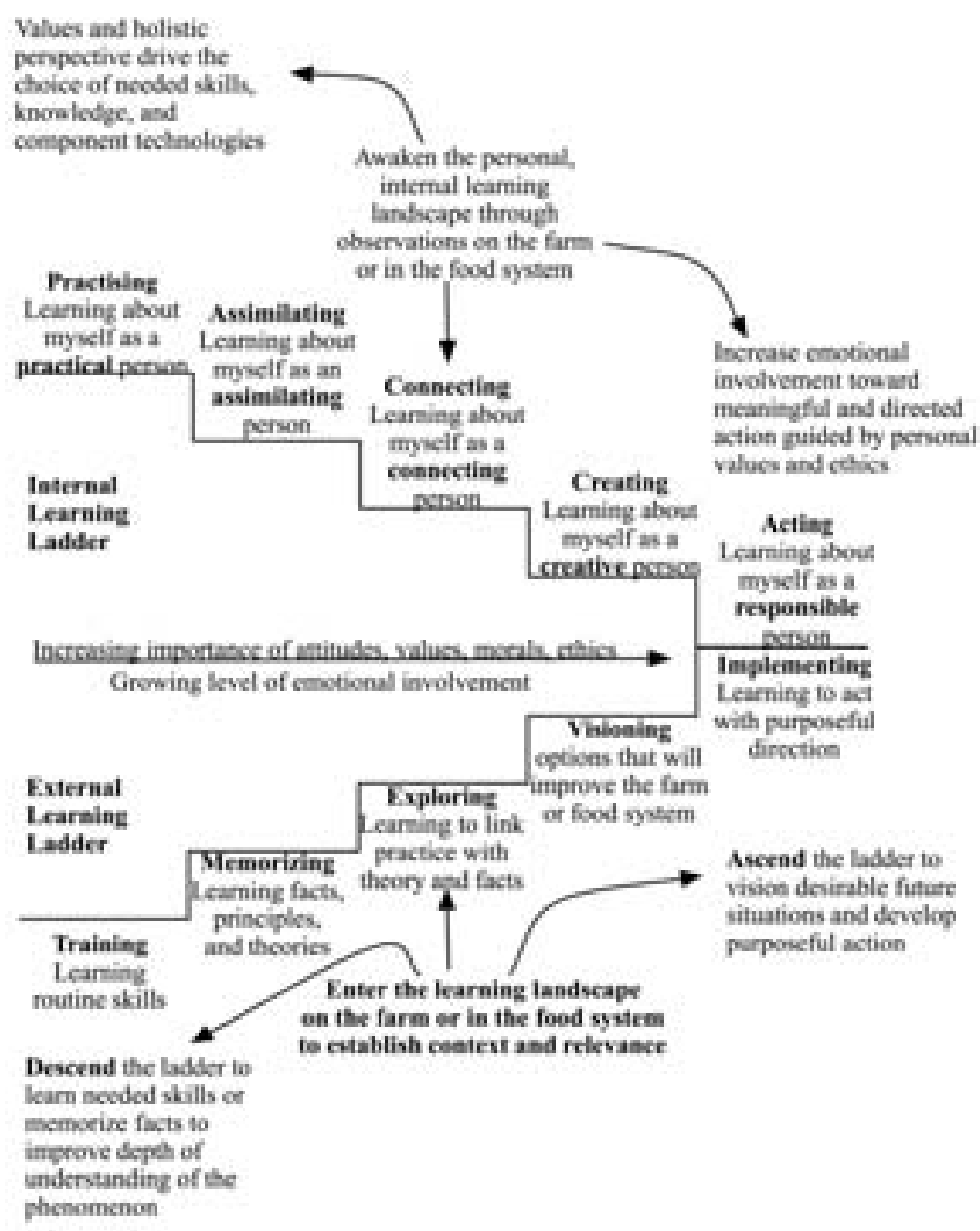

Figure 1. Steps on the dual learning ladder towards responsible action as agroecologists (adapted from Lieblein et al., 2007).

acquired through training, and learning facts, principles and theories can be memorized and hopefully internalized for application in new situations. Moving up the ladder we find the entry point for our education program in agroecology, where students begin at the level of the farming or food system and use their past knowledge to link practice with theory. They move back down the ladder to acquire more information as needed. When there is enough confidence to move toward action, students (often in teams) begin to envision future options that can improve the farm or food system according to the goals and philosophy of the farmer and family or the key client in the community. With these visions well evaluated, the student is ready to move to implement change in a responsible way.

When we look at this ladder and compare the steps to most of our conventional courses in agricultural sciences, it is obvious that most attention is given to the lower rungs on the ladder. There is no question of the importance of a strong foundation in skills, knowledge, principles, and theories in any discipline. Yet when these are not placed in context, they are often not very exciting to students who are impatient, action oriented, and part of the cell phone and text message generation. Entering the learning process by starting on the farm or exploring a community food system appears to bring some immediate relevance to learning, at least in our experience in the Nordic Region. Students enter the learning landscape on the farm or in the community, and descend the ladder to pick up needed skills or information. They ascend the ladder to work on potential future scenarios and move toward purposeful action. 
In courses in agronomy we do offer applications, and often discuss how the results of experiments can be applied on the farm. We also discuss future practices and how they may be important as systems change in response to regulation, resource availability, or economics. Yet we still concentrate on the comfort zones near the bottom of the learning ladder shown in Figure 1. After all, this is how we learned, so it should be good enough for the next generation. At times we wonder why students are not coming to our conventional courses and majors, and are not intrinsically motivated to learn the basic sciences. We need to seek ways to improve education so that they will be excited and attracted and leave our universities prepared to face a complex future.

What characterizes the other ninety percent of the learning that takes place outside the classroom, is not apparent on papers or tests, or is otherwise not observed by us as instructors? We don't offer insight on how to observe or measure this type of learning, although some experienced instructors would say it is intuitive. Figure 1 (upper part) shows the possible steps in a personal learning process. In the figure, we speculate that students practice to perfect their skills, and learn about themselves as practical people. Internalizing knowledge, theories, and facts and organizing these based on prior experience and that in the classroom, students assimilate information and become better prepared to apply this to new situations. By starting on the farm or in the community, students begin by connecting what they know to the real world, and prepare for creating potential visions for the future. After these visions are described in enough detail that their impacts can be estimated, students can work with clients to weigh the potential consequences of each strategy and then move with confidence toward action as a responsible and informed person. Although we apply this in agroecology, again we suggest that the process could be followed in any practical development context.

Other dimensions of the learning activities that can be extracted from the metaphor include a movement from the known knowledge environment on the left side to an unknown situation on the right side. We also suggest that moving from the concrete skills, facts and theories toward application and visioning together with clients includes an increasing importance of at- titudes, value, morals, and ethics. This could be accompanied by a growing level of emotional involvement. The activities and the consequences are no longer just a grade on a paper or a completion of an exercise, but they relate to real people and circumstances that will affect their financial and emotional well being as a consequence of change. This raises the stakes for both students and instructors, and may be just what we need to attract motivated people to our programs.

\section{Conclusions}

Agroecology expands the traditional production focus in agriculture by including social and ecological dimensions. It further provides concepts and tools for understanding and dealing with farming and food systems as whole entities, without breaking them down to their component parts. In agroecological education in the Nordic region we have moved the point of departure from the positivist input-response approach of traditional agricultural education, focusing on systems components, to a dialogue and experiential based approach where exploration of farming and food systems are integrated with relevant theory on concepts and methods. The dual ladder of agroecological education helps our understanding of how the students can practice a diverse mix of cognitive and personal learning elements, as necessary steps towards responsible action as professionals.

"I learned a lot about vision thinking, systemic thinking, and how to work in groups. But best of all it changed my life and focus for the rest of my education. It gave me the courage to follow my dreams and interests, which has put me in a great situation now. I also learned how essential learning is and how the ideas about learning can be used in many aspects of life, professionally as well as privately" (Quote from a student in 2002, quoted in Lieblein et al., 2007).

\section{References}

Allen P. 2004. Together at the table: sustainability and sustenance in the American agrifood system. Penn State University Press, University Park, Pennsylvania, USA.

Altieri M.A. 1995. Agroecology: the science of sustainability, $2^{\text {nd }}$ Edition. Westview Press, Boulder Colorado, U.S.A. 
Altieri M.A., Francis C.A. 1992. Incorporating agroecology into the conventional agricultural curriculum. Amer. J. Altern. Agric., 7:89-93.

Altieri M.A., Nicholls C.I. 2005. Agroecology and the search for a truly sustainable agriculture. United National Environment Program, Environmental Network for Latin America and the Caribbean, Mexico D.F., Mexico. [available on line at http://www.agreco.org/doc/agroecology-engl-PNUMA.pdf]

ASA. 2006. JNRLSE Case Studies, 1992-2005. American Society of Agronomy, Madison, Wisconsin, U.S.A.

Bawden R.J. 1989. Systems agriculture: learning to deal with complexity. Ballantine Press, New York, U.S.A.

Bloom B.S. 1956. Taxonomy of educational objectives, Handbook I: the cognitive domain. David McKay Co, New York.

Bowden J., Marton F. 1998. The university of learning: beyond quality and competence in higher education. Kogan Page Limited, London, U.K.

Brown L.R. 2006. Plan B 2.0. Rescuing a planet under stress and a civilization in trouble. Earth Policy Institute, Washington DC.

Caporali F. 1991. Ecologia per l'agricoltura. Utet-Libreria, Torino.

Checkland P. 1981. Systems thinking, systems practice. John Wiley \& Sons, Chichester, U.K.

Dalgaard T., Hutchings N.J., Porter J.R. 2003. Agroecology, scaling, and interdisciplinarity. Agric., Ecosystems, and Environment, 100:39-51.

Dewey J. 1942. Democracy and education. Macmillan Publ., New York, U.S.A.

Foyster J. 1990. Getting to Grips with CompetencyBased Training and Assessment. TAFE National Centre for Research and Development: Leabrook, Australia. ERIC: ED 317849.

Francis C., Lieblein G., Gliessman S., Breland T.A., Creamer N., Harwood R., Salomonsson L., Helenius J., Rickerl D., Salvador R., Wiedenhoeft M., Simmons S., Allen P., Altieri M., Flora C., Poincelot R. 2003. Agroecology: the ecology of food systems. J. Sustainable Agric., 22:99-118.

Friederichs K. 1930. Die Grundfragen und Gesetzmässigkeiten der land- und forstwirtschaftlichen zoologie, Berlin. In: Tischler W. (ed.): Agrarökologie. Gustav Fischer Verlag, Jena. 499 p.

Gliessman S.R. 2006. Agroecology: ecological processes in sustainable agriculture, $2^{\text {nd }}$ Edition. CRC Press, Boca Raton, Florida, U.S.A.
Gliessman S.R. 2001. Agroecosystem sustainability: developing practical strategies. CRC Press, Boca Raton, Florida, U.S.A.

Hanson H.C. 1939. Ecology in agriculture. Ecology, 20:111-117.

Kimbrell A. (ed.) 2002. Fatal harvest: the tragedy of industrial agriculture. Island Press, Washington, DC, U.S.A.

Kolb D. 1984. Experiential learning: experiences as a source of learning and development. Prentice Hall Publ., Englewood Cliffs, New Jersey, U.S.A.

Lave J., Wenger E. 1991. Situated learning: legitimate peripheral participation. Cambridge University Press, Cambridge, U.K.

Lieblein G., Francis C.A., Salomonsson L., Sriskandarajah N. 1999. Ecological agriculture research: increasing competence through PhD courses. J. Agric. Education and Extension, 6:31-46.

Lieblein G., Francis C., Barth Eide W., Torjusen H., Solberg S., Salomonsson L., Lund V., Ekblad G., Persson P., Helenius J., Loiva M., Sepannen L., Kahiluoto H., Porter J., Olsen H., Sriskandarajah N., Mikk M., Flora C. 2000. Future education in ecological agriculture and food systems: a student-faculty evaluation and planning process. J. Sustain. Agric. 16:49-69.

Lieblein G., Østergaard E., Francis C. 2004. Becoming an agroecologist through action education. J. Agricultural Sustainability (U.K.), 2:147-153.

Lieblein G., Breland T.A., Salomonsson L., Østergaard E., Francis C. 2007. Educational perspectives in agrecology: steps on a dual learning ladder toward responsible action. NACTA J. March: 34-44.

Richards B. 1985. Performance Objectives as the Basis for Criterion-Referenced Performance Testing. J. of Industrial Teacher Education, 22:28-37.

Salomonsson L., Francis C.A., Lieblein G., Furugren B. 2005. Just in Time Education. NACTA J. December 49:5-13.

Sriskandarajah N., Bawden R.J., Packham R.G. 1991. Systems agriculture: a paradigm for sustainability. AFSRE Newsletter, 2:1-5.

Tilman D., Cassman K.G., Matson P.A., Naylor R. 2002. Agricultural sustainability and intensive production practices. Nature, 418 (8 August):671-677.

Wilson K., Morren Jr. G.E.B. 1990. Systems approaches for improvement in agriculture and resource management. Macmillan Publishing Co., New York, U.S.A. 